\title{
ЕВРОПЕЙСКИЕ ВЫБОРЫ 2019 г: СТАТИСТИКА И ПРОГНОЗЫ
}

\begin{abstract}
Аннотация. 23-26 мая 2019 г. в 28 странах - членах Европейского союза прошли выборы депутатов Европейского парламента. Они вызвали значительный интерес у граждан этих стран. Уэе известны предварительные результаты, которые в ряде случаев оказались весьма неожиданными. Самый главный итог - завершение существования двухпартийной политической системы в ЕС, основу которой составляли Европейская народная партия и партия Европейских соииалистов. Автор статьи делает попытку найти и обосновать причины, которые привели к таким результатам, и дать прогноз дальнейшего развития ситуации с формированием новых политических институтов Евросоюза (руководства самого Европарламента, Еврокомиссии, Европейского совета, Европейского Центробанка).
\end{abstract}

Ключевые слова: Европейский союз (ЕС), выборы, Европарламент (ЕП), европейские партии, евроскептики.

\section{Общие итоги выборов}

Выборы нового состава Европарламента, прошедшие во всех 28 странах Евросоюза 2326 мая 2019 г. в условиях значительного роста явки, знаменовали собой завершение существования двухпартийной политической системы, включающей Европейскую народную партию (ЕНП) и партию Европейских социалистов (ПЕС). Скорее всего, в новом составе Европарламента будет создана проевропейская трёх- и возможно четырёхпартийная коалиция большинства, в которую помимо фракций ЕНП и ПЕС войдёт фракция Альянса либералов и демократов Европы (АЛДЕ) и с малой долей вероятности фракция Зелёные - Европейский свободный альянс (3-ЕСА). Успех евроскептиков (в первую очередь жёстких - Европа наций и свобод (ЕНC)) хотя и имел место (они увеличили своё представительство практически в 2 раза), но оказался далеко не таким значимым, как считали некоторые эксперты, политики и журналисты.

Однако формирование окончательного состава фракций и назначение тех, кто возглавит ведущие политические институты Евросоюза, будут сложными, и могут сопровождаться некоторым сюрпризам.

В таблице 1 представлены предварительные результаты выборов в Европарламент по всем странам - членам ЕС.

Исходя из этих данных, скорее всего, в новом составе Европарламента будет сформировано 7 фракций: 4 проевропейских - ЕНП, ПАСД, АЛДЕ и 3-ЕСА, имеющих в сумме 511 депутатов (ДЕП), и три евроскептических: две мягких евроскептиков Европейские консерваторы и реформисты (ЕКР), в составе 64 депутатов и Европейские левые-Левые зелёные Севера (ЕЛЛЗС), в составе 38 депутатов и одна жёстко евроскептическая ЕНС в составе 58 депутатов.

(C) Гуселетов Борис Павлович - доктор политических наук, ведущий научный сотрудник Центра партийно-политических исследований Отдела социальных и политических исследований Института Европы РАН. Adpec: 125009, Россия, Москва, ул. Моховая, д. 11, стр. 3. E-mail: bgusletov@mail.ru.

DOI: http://dx.doi.org/10.15211/vestnikieran320191116 
Таблица 1

Предварительные результаты выборов в Европарламент по всем странам - членам ЕС 1

\begin{tabular}{|c|c|c|c|c|c|c|c|c|c|c|c|}
\hline № & Страна & Число ДЕП & ЕНП & ПАСД & АЛДЕ & 3-ECA & EKP & EHC & ЕСПД & ЛЕ-ЛЗС & Нов.+ нез. \\
\hline 1 & Австрия & 18 & 7 & 5 & 1 & 2 & - & 3 & - & - & - \\
\hline 2 & Бельгия & 21 & $2+1+1$ & $2+1$ & $2+2$ & $2+1$ & 3 & 3 & - & 1 & - \\
\hline 3 & Болгария & 17 & $6+1$ & 5 & 3 & - & 2 & - & - & - & - \\
\hline 4 & Великобр. & 73 & - & 10 & $15+1$ & 11 & 4 & - & 29 & 1 & $1+1$ \\
\hline 5 & Венгрия & 21 & 13 & $4+1$ & 2 & - & - & - & - & - & 1 \\
\hline 6 & Германия & 96 & 29 & 16 & $5+2$ & $22+1+1$ & 1 & - & 11 & 5 & $2+1$ \\
\hline 7 & Голландия & 26 & 4 & 6 & $4+2$ & 3 & 5 & - & - & 1 & 1 \\
\hline 8 & Греция & 21 & 8 & 2 & - & - & 1 & - & - & 6 & $2+2$ \\
\hline 9 & Дания & 13 & 1 & 3 & $3+2$ & 2 & 1 & - & - & 1 & - \\
\hline 10 & Ирландия & 11 & 4 & - & 1 & 2 & - & - & - & $1+1$ & 2 \\
\hline 11 & Испания & 54 & 12 & 20 & $7+1$ & 3 & - & - & - & 6 & $3+2$ \\
\hline 12 & Италия & 73 & $6+1$ & 19 & - & - & 5 & 28 & 14 & - & - \\
\hline 13 & Кипр & 6 & 2 & $1+1$ & - & - & - & - & - & 2 & - \\
\hline 14 & Латвия & 8 & 2 & 2 & - & 1 & 2 & - & - & - & 1 \\
\hline 15 & Литва & 11 & 3 & 2 & 2 & 2 & 1 & - & - & - & 1 \\
\hline 16 & Люксембург & 6 & 2 & 1 & 2 & 1 & - & & - & - & - \\
\hline 17 & Мальта & 6 & 2 & 4 & - & - & - & - & - & - & - \\
\hline 18 & Польша & 51 & 17 & $5+3$ & - & - & 26 & - & - & - & - \\
\hline 19 & Португалия & 21 & $6+1$ & 9 & - & 1 & & & & $2+2$ & \\
\hline 20 & Румыния & 32 & $10+2+2$ & 9 & 8 & - & 1 & - & - & - & - \\
\hline 21 & Словакия & 13 & $2+1+1$ & 3 & 2 & - & 2 & - & - & - & 2 \\
\hline 22 & Словения & 8 & $3+1$ & 2 & 2 & - & - & - & - & - & \\
\hline 23 & Финляндия & 13 & 3 & 2 & $2+1$ & 2 & 2 & - & - & 1 & - \\
\hline 24 & Франция & 74 & 8 & 5 & 21 & 12 & - & 22 & - & 6 & - \\
\hline 25 & Хорватия & 11 & 4 & 3 & 1 & - & 1 & - & & - & $1+1$ \\
\hline 26 & Чехия & 21 & $3+2$ & - & 6 & 3 & 4 & 2 & - & 1 & - \\
\hline 27 & Швеция & 20 & $4+2$ & 5 & $2+1$ & 2 & 3 & - & - & 1 & - \\
\hline 28 & Эстония & 6 & - & 2 & $2+1$ & - & - & - & - & - & 1 \\
\hline & ВСЕГО & 751 & 179 & 153 & 106 & 74 & 64 & 58 & 54 & 38 & 25 \\
\hline
\end{tabular}

29 депутатов от партии Брекзит (Великобритания), 14 - от партии «Движение 5 звёзд» (Италия) и 11 - от партии «Альтернатива для Германии» (АдГ) вряд ли смогут реанимировать группу Европа свободы и прямой демократии (ЕСПД), т.к. им необходимо будет привлечь в свой состав представителей ещё 4 стран - членов Европейского союза ${ }^{2}$. Скорее всего, после 31 октября 2019 г., когда должен будет завершиться процесс выхода Великобритании из ЕС, депутаты от партии Брекзит покинут Европарламент. Поэтому, с большой долей вероятности, депутаты от этих партий присоединятся частично к ЕКР, а частично к ЕНС, но в какой пропорции - пока что трудно сказать.

\section{Фено́мен заметного роста явки}

Первая отличительная особенность этих выборов - явка, которая составила 50,95\% во всех 28 государствах - членах, что на 8,34 пункта выше по сравнению с выборами 2014 г. Это самый высокий показатель после выборов 1994 г. (56,67\%, в то время ЕС включал только 12 стран-членов). На рисунке 1 даны результаты явки по отдельным странам - членам ЕС.

В пяти странах - Австрии, Германии, Дании, Словакии и Чехии явка выросла примерно на 10 пунктов и более. В четырёх - Венгрии, Испании, Польше, Румынии рост составил более 15 пунктов.

В отличие от выборов 2014 г. ни в одной стране не была зафиксирована явка ниже $20 \%$.

\footnotetext{
${ }^{1}$ Сайт Европарламента. 2019 European election results. URL: https://www.election-results.eu/seats-political-groupcountry/2019-2024/ (дата обращения: 10.06.2019).

${ }^{2}$ Согласно регламенту работы Европарламента для создания политической группы необходимо, чтобы в её состав входило 35 депутатов, представляющих не менее 7 стран - членов ЕС.
}

Научно-аналитический вестник ИЕ РАН, 2019, №3 
Рисунок 1

Результаты явки по всем странам - членам ЕС на выборах депутатов Европарламента 2019 г. ${ }^{1}$

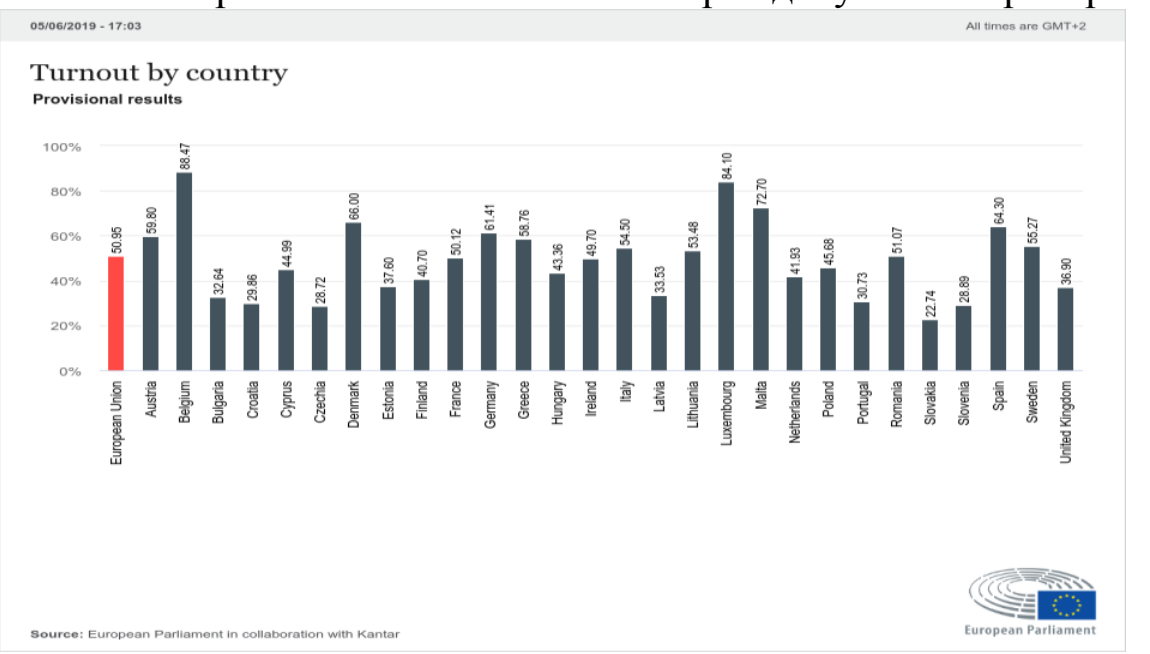

Если исключить Бельгию и Люксембург, где участие в голосовании обязательно, явка ни в одной стране не превышала $66 \%$.

Поскольку явка превысила символическую отметку в 50\%, результаты этих выборов придают большую демократическую легитимность Европарламенту с учётом широкого разнообразия представленных в нём политических сил. Это также свидетельствует о том, что всё больше европейских граждан считают, что вопросы, вызывающие их наибольший интерес (безопасность, миграция, экономика и социальная сфера, климат), должны найти свой ответ на европейском уровне.

Национальные факторы также сыграли важную роль в избирательной кампании, в выборе избирателей и в увеличении явки. Но место европейских вопросов в этих дебатах, особенно на национальном уровне, свидетельствует о растущей европеизации политики в государствах-членах.

\section{Завершение функционирования двухпартийной системы на уровне ЕС}

Как было сказано, одним из главных итогов этих выборов стало завершение функционирования двухпартийной системы, действовавшей с 1979 г. В представленной ниже таблице 2 даны предварительные результаты выборов депутатов Европарламента 2019 г. и их сравнение с результатами предыдущих выборов 2014 г.

Две основные общеевропейские партии (ЕНП и ПЕС) будут иметь самые многочисленные фракции, соответственно, 179 и 153 депутата. Но численность этих фракций заметно уменьшились по сравнению с 2014 г. (см. табл. 2), и теперь они уже не будут иметь на двоих большинства в Европарламенте.

Хотя ЕНП в этот раз победила в 14 странах (даже в Греции и Румынии, где её партиичлены не входят в состав правительств), в ряде других стран партии - члены ЕНП потерпели серьёзное поражение. Во Франции Республиканцы теперь имеют только 8 депутатов (-8 по сравнению с 2014 г.), в Италии «Вперёд, Италия!» будет иметь 6 депутатов (-5), а в Испании Народная партия (ПП) будет иметь 12 депутатов (-4).

В ПЕС только Социалистическая рабочая партии Испании, Соцпартия в Португалии и Лейбористская партия Голландии сумели сохранить лидирующие позиции. В ряде других

\footnotetext{
${ }^{1}$ Сайт Европарламента. 2019 European election results. URL: https://www.election-results.eu/0004.png (дата обращения: 10.06.2019).
}

Научно-аналитический вестник ИЕ РАН, 2019, №3 
Таблица 2

Предварительные результаты выборов депутатов Европарламента 2019 г.

и их сравнение с результатами предыдущих выборов 2014 г. $^{1}$

\begin{tabular}{|c|c|c|c|c|}
\hline № & \begin{tabular}{|c|} 
Название поли- \\
тической группы \\
\end{tabular} & Партия, которую представляет группа & \begin{tabular}{|c|} 
Число ДЕП в 2014 \\
г. (\% от общ. числа)
\end{tabular} & $\begin{array}{c}\text { Число ДЕП, в } 2019 \text { г. } \\
\text { (\% от общ. числа) }\end{array}$ \\
\hline 1 & ЕНП & Европейская народная партия (ЕНП) & $216(28,7 \%)$ & $179(23,83 \%) / \mathbf{1 6 8}$ \\
\hline 2 & ПАСД & Партия европейских социалистов (ПЕС) & $187(24,9 \%)$ & $153(20,37 \%) / 146$ \\
\hline 3 & АЛДЕ & Альянс либералов и демократов за Европу (АЛДЕ) & $69(9,2 \%)$ & $106(14,11 \%) / 106$ \\
\hline 4 & 3-ECA & Европейская партия зелёных (ЕПЗ) & $52(6,9 \%)$ & $74(9,85 \%) / 55$ \\
\hline 5 & EКР & Альянс европейских консерваторов и реформистов & $77(10,25 \%)$ & $64(8,52 \%) / 59$ \\
\hline 6 & EHC & Европа наций и свобод (ЕНС) & $36(4,8 \%)$ & $58(7,72 \%) / 74$ \\
\hline 7 & $\begin{array}{l}\text { ЕСПД (Брекзит } \\
+Д 53+\text { АдГ) }\end{array}$ & & $42(5,6 \%)$ & $54(7,19 \%) / 48$ \\
\hline 8 & ЕЛ-ЛЗС & Партия европейских левых (ПЕЛ) & $52(6,9 \%)$ & $38(5,06 \%) / 52$ \\
\hline 9 & \begin{tabular}{|l} 
Новые партии + \\
независимые
\end{tabular} & & $20(2,65 \%)$ & $16+9=25(3,33 \%) / 43$ \\
\hline & ВСЕГО & & $751(100 \%)$ & $751(100 \%)$ \\
\hline
\end{tabular}

стран партии - члены ПЕС потерпели неудачу, немецкая СДПГ потеряла 11 мест, Демократическая партия Италии - 12, СДП в Румынии - 4 места, а Соцпартия Франции вообще получила наихудший результат в своей истории - 5 мест $(6,19 \%)$. В Чехии, где ещё недавно социалдемократы были правящей партией, на этот раз ни один из её представителей не был избран в Европарламент.

\section{Новое проевропейское большинство}

Проевропейские политические силы по-прежнему сохранят большинство в Европарламенте, занимая 66,25\% мест. Помимо фракций ЕНП и ПЕС к новому парламентскому большинству могут присоединиться ещё две фракции - либералов (АЛДЕ) и, может быть, зелёных (3-ECA), с которыми они, по всей вероятности, объединят усилия для формирования нового большинства. Либералы сумели увеличить численность своей группы на 37 депутатов по сравнению с 2014 г., став третьей группой в Европарламенте.

Зелёные также существенно увеличили численность своей фракции на 22 депутата и вышли на четвёртое место, особенно благодаря отличным результатам в Германии, где они заняли второе место после ХДС/ХСС, опередив СДПГ, а также в ряде других стран - членов: Бельгии, Нидерландах и Франции. ЕНП и ПЕС предстоят непростые переговоры с представителями этих политических групп, чтобы включить одну или обе в новую коалицию большинства.

\section{О перспективах евроскептиков}

В уходящем составе Европарламента евроскептики имели 4 фракции, три мягких евроскептиков (ЕКР, ЕСПД и ЕЛ-ЛЗС) и одну жёстких евроскептиков (ЕНС), которые суммарно имели 206 депутатов (27,55\%), причём ЕНС была самой малочисленной в ЕП. В новом составе Европарламента общее число евроскептиков составит 214 депутатов (28,5\%). В целом им не удалось существенно увеличить своё представительство в Европарламенте нового созыва.

Очевидно, что сохранятся две правые фракции: ЕКР, которая будет иметь 64 депутата (-13) и станет 5-й по численности, и ЕНС, которая теперь будет иметь минимум 58 депутатов

\footnotetext{
${ }^{1}$ Сайт Европейского парламента. European Elections 2019 Results. URL: https://www.election-results.eu/ (дата обращения: 10.06.2019). Жирным шрифтом выделены прогнозные данные о результатах выборов в Европарламент, представленные компанией POLITICO 21 мая 2019 г. URL: https://www.politico.eu/2019-european-elections/\#93156 (дата обращения: 21.05.2019).
}

Научно-аналитический вестник ИЕ РАН, 2019, №3 
(+22 по сравнению с 2014 г. за счёт успеха партии «Лига», Италия) и станет 6-й по численности, а также одна левая фракция ЕЛ-ЛЗС - 38 депутатов (-14 ДЕП). Бывшая фракция ЕСПД, основу которой в прошлом Европарламенте составляли Партия независимости Объединённого королевства Н. Фараджа и партия «Движение 5 звезд» (Д53) в новом составе ЕП вряд ли сумеет сохраниться. Хотя на выборах 2019 г. новая партия Фараджа Брекзит вновь заняла в Великобритании первое место и будет иметь 29 депутатов, а Д53 сохранила своих 14 депутатов, пока к ним готовы присоединиться 11 депутатов от АдГ. Учитывая общую неясность с перспективами депутатов от Великобритании, в случае завершения брекзита вряд ли эти три партии сумеют найти себе новых партнёров до конца июня этого года. Скорее всего, депутаты от Д53 полностью или частично войдут в другую евроскептическую фракцию правого толка - ЕКР или ЕНС.

Весьма вероятно, что разногласия между различными фракциями евроскептиков, которые имели место и ранее сохранятся и вряд ли они смогут наладить какую-то координацию между собой. Стоит также отметить, что эта избирательная кампания оказалась трагичной для двух евроскептических партий, входивших в правительства своих стран: праворадикальной австрийской партии Свободы Штрахе и леворадикальной греческой партии СИРИЗА Ципраса. В результате в Австрии и Греции осенью этого года предстоят досрочные парламентские выборы, и совсем не факт, что обе эти партии смогут вновь войти в состав правительств своих стран.

\section{О перспективах избрания нового руководства ведущих политических институтов ЕС}

После начала своей работы 1 июля 2019 г. новому составу Европарламента предстоит избрать себе новых руководителей (председателя и его заместителей, глав комитетов и комиссий), а потом решить главный вопрос выбора нового Председателя Еврокомиссии и 28 еврокомиссаров, а также главу ЕЦБ. Что касается выборов главы ЕП, то, скорее всего, будет сохранена традиция, когда половину срока (2,5 года) его возглавлял представитель ЕНП, а другую половину - представитель НАСД. Хотя не исключено, что фракция АЛДЕ попытается предложить свою кандидатуру на этот пост. Большинство постов руководителей комитетов и комиссии Европарламента также останутся за этими тремя группами, возможно, по одному месту получат представители Зелёных и ЕКР.

Но самая главная борьба развернётся за пост главы Еврокомиссии. Сейчас главным кандидатом на это пост является Манфред Вебер из ЕНП, который был так называемым шпиценкандидатом от этой партии, которая победила на выборах. Но его кандидатура вызывает много вопросов из-за отсутствия у него опыта работы в органах исполнительной власти на европейском уровне. Да и вряд ли представителям большинства стран - членов Евросоюза понравится, что депутат от Германии, которая и так доминирует в ЕС, займёт ещё и пост главы европейского правительства. Поэтому не случайно уже начались предварительные переговоры между главами ряда стран - членов ЕС, представляющих ЕНП, ПЕС и АЛДЕ о возможном кандидате на этот важный пост ${ }^{1}$. Среди главных претендентов помимо М. Вебера фигурируют шпицекандидат от ПЕС, первый заместитель нынешнего главы Комиссии и бывший министр иностранных дел Нидерландов Франс Тиммерманс, бывший министр иностранных дел Франции и еврокомиссар Мишель Барнье, комиссар ЕС по конкуренции Маргрета Вестагер и лидер группы АЛДЕ в Европарламенте, бывший премьер-министр Бельгии Ги Верхофштадт.

И хотя ЕНП имеет относительное большинство в Европарламенте, не стоит забывать,

\footnotetext{
${ }^{1}$ Herszenhorn D.M., de La Baume M., Barigazzi J. Last supper of the Spitzenkandidaten. 6 prime ministers gathered for dinner in Brussels to discuss how to fill EU leadership jobs. URL: https://www.politico.eu/article/last-supper-of-thespitzenkandidaten/ (дата обращения: 21.05.2019).
} Научно-аналитический вестник ИЕ РАН, 2019, №3 
что вместе ПАСД и АЛДЕ имеют больше депутатов, чем ЕНП (259 против 179). Кроме того, в Европейском совете, который включает глав всех стран - членов ЕС и который, в конечном итоге, будет представлять Европарламенту кандидата на этот пост, АЛДЕ И ПАСД имеют 15 представителей против 8 у ЕНП. Так что игра ещё далеко не окончена.

\section{Выводы}

Новые фракции Европарламента начнут обсуждение перспектив их будущей деятельности, и здесь не исключены некоторые сюрпризы, связанные, например, с конфигурацией нового большинства в ЕП, позицией депутатов от Великобритании и представителей новых партий и др. Но вряд ли всё это приведёт к радикальной перемене ситуации внутри Европарламента.

Не менее важны и переговоры между главами государств и правительств, которые уже неформально начались с конца мая, по поводу избрания новых руководителей ведущих политических институтов ЕС новым составом Европарламента (сам ЕП, Европейская комиссия, Европейский совет, Европейский Центробанк). Они должны будут обеспечить согласование интересов между различными политическими силами Европейского союза, с учётом итогов выборов, а также территориального и гендерного балансов.

\section{Список литературы/References}

2019 European election results. European Parliament. URL https://www.electionresults.eu/seats-political-group-country/2019-2024/ (дата обращения: 10.06.2019).

2019 European election results. European Parliament. URL: https://www.electionresults.eu/0004.png (дата обращения: 10.06.2019).

European elections. POLITICO. URL: https://www.politico.eu/2019-european-elections/\#93156 (дата обращения: 21.05.2019).

Herszenhorn D.M., de La Baume M., Barigazzi J. Last supper of the Spitzenkandidaten. 6 prime ministers gathered for dinner in Brussels to discuss how to fill EU leadership jobs. URL: https://www.politico.eu/article/last-supper-of-the-spitzenkandidaten/ (дата обращения: 21.05.2019).

\section{European Elections 2019: statistics and forecasts}

Author. Boris Guseletov, Doctor of Sciences (Politics), Leading Research Associate, Centre for Parties and Political Studies of the Department of Social and Political Studies, Institute of Europe, Russian Academy of Sciences. Address: 11-3, Mokhovaya str., Moscow, Russia, 125009. Email: bgusletov@mail.ru.

Abstract. On May 23-26, 2019 elections of the European Parliament deputies were held in 28 member States of the European Union. The elections aroused considerable interest among the citizens of these countries. Their preliminary results elections are already known, and in some cases they turned out to be quite unexpected. The most important result of the elections is the end of the existence of a bipartisan political system in the EU, which was based on the European people's party and the party of European socialists. The author tries to find and justify the reasons that led to such results and give a forecast for the further development of the situation with the formation of new political institutions of the European Union, which will be updated following the results of these elections (the leadership of the European Parliament, the European Commission, the European Council, the European Central Bank).

Keywords: European Union, elections, European Parliament, European parties, eurosceptics.

DOI: http://dx.doi.org/10.15211/vestnikieran320191116 